\title{
Progressive renal toxicity due to ifosfamide
}

\author{
D Heney, J Wheeldon, P Rushworth, C Chapman, I J Lewis, C C Bailey
}

\begin{abstract}
A prospective and follow up study of renal tubular and glomerular function in 11 children receiving ifosfamide treatment was conducted. Each child received between four and 14 courses of ifosfamide, given as a continuous infusion of $3 \mathrm{~g} / \mathrm{m}^{2}$ over 24 hours for two or three days. Evidence of renal toxicity was seen in all patients. There was a treatment related rise in urinary tubular markers (N-acetyl-glucosaminidase and $\alpha_{1}$ microglobulin). Recovery was limited, so that by the fourth course of treatment all values remained abnormal. There was an associated treatment related reduction in plasma phosphate concentration. Urinary albumin also showed a treatment related rise, but with fewer abnormal values. Electrophoresis was used to confirm tubular or glomerular patterns. Glomerular toxicity was less severe and occurred in fewer patients. The follow up study showed persistence of tubular damage in all seven patients examined, and there was evidence of glomerular damage in five of the seven children. Children receiving ifosfamide need to be carefully monitored for renal toxicity both during treatment and at follow up.
\end{abstract}

Before 1980 ifosfamide was precluded from use in children because of its severe renal and bladder toxicity. However, with the introduction of mesna, a uroprotector, ifosfamide has occupied an increasingly important role in solid tumour protocols. While the debate over its efficacy in comparison to cyclophosphamide continues, ${ }^{1}$ there are also concerns with regard to its renal toxicity.

There have been a number of case reports of
Fanconi's syndrome developing both during treatment, ${ }^{2}$ and more frequently, in patients after completion of treatment. ${ }^{34} \mathrm{~A}$ cross sectional follow up study has shown combined glomerular and tubular damage presumed to be caused by ifosfamide. ${ }^{5}$ Goren et al have shown subclinical tubular damage associated with individual ifosfamide treatments, but could find little evidence of progressive nephrotoxicity in children with normal renal function. ${ }^{6}$ In order to define more closely the association between ifosfamide and renal toxicity we have performed a combined prospective and follow up study of both tubular and glomerular function in a group of children treated with ifosfamide.

\section{Patients and methods}

\section{PATIENTS}

The prospective part of this study was performed over a 12 month period at St James's University Hospital. All children being treated with regular courses of ifosfamide were included. Only one child, an 18 month old boy, was excluded because of an inability to collect satisfactory urine samples. A follow up study was subsequently performed on the same group of children.

Eleven children were studied. Their details are given in table 1 . Their mean age was 7 years. Five of the children were being treated for relapsed disease. No child was receiving platinum based compounds. All had normal renal function at the start of treatment, as indicated by normal concentrations of plasma creatinine, electrolytes, and phosphate, a normal glomerular filtration rate (GFR) as measured by clearance of diethylenetriamine pentacetic acid (DTPA), and no glycosuria or proteinuria

Department of
Paediatrics and
Child Health,
St James's University
Hospital,
Leeds LS9 7TF
D Heney
J Wheeldon
I J Lewis
C C Bailey
Department of
Chemical Pathology,
The General Infirmary
at Leeds
P Rushworth
C Chapman
Correspondence to:
Dr Heney.
Accepted 20 April 1991

Table 1 Patient characteristics

\begin{tabular}{|c|c|c|c|c|c|c|}
\hline No/sex & $\begin{array}{l}\text { Age } \\
\text { (years) }\end{array}$ & Diagnosis & Disease status & $\begin{array}{l}\text { Total } \\
\text { dose of } \\
\text { ifosfamide } \\
\left(\mathrm{g} / \mathrm{m}^{2}\right)\end{array}$ & Previous treatment & $\begin{array}{l}\text { Glomerular } \\
\text { filtration rate } \\
(\mathrm{ml} / \mathrm{min} / \\
\left.1 \cdot 73 \mathrm{~m}^{2}\right)\end{array}$ \\
\hline $1 / M$ & 3 & Neuroblastoma & Relapsed & 36 & $\begin{array}{l}\text { Vincristine, cyclophosphamide, } \\
\text { cisplatin, teniposide }\end{array}$ & 125 \\
\hline $\begin{array}{l}2 / M \\
3 / M \\
4 / M \\
5 / M \\
6 / F\end{array}$ & $\begin{array}{l}3 \\
5 \\
5 \\
5 \\
7\end{array}$ & $\begin{array}{l}\text { Rhabdomyosarcoma } \\
\text { Wilms' tumour } \\
\text { Rhabdomyosarcoma } \\
\text { Rhabdomyosarcoma } \\
\text { PNET* }\end{array}$ & $\begin{array}{l}\text { Newly diagnosed } \\
\text { Relapsed } \\
\text { Newly diagnosed } \\
\text { Newly diagnosed } \\
\text { Relapsed }\end{array}$ & $\begin{array}{r}85 \\
63 \\
108 \\
99 \\
36\end{array}$ & $\begin{array}{l}\text { Nil } \\
\text { Vincristine, actinomycin } \\
\text { Nil } \\
\text { Nil } \\
\text { Vincristine, actinomycin, } \\
\text { cyclophosphamide }\end{array}$ & $\begin{array}{l}126 \\
140 \\
137 \\
130 \\
170\end{array}$ \\
\hline $\begin{array}{l}7 / \mathbf{M} \\
8 / \mathbf{F}\end{array}$ & $\begin{array}{l}8 \\
8\end{array}$ & $\begin{array}{l}\text { Ewing's tumour } \\
\text { Wilms' tumour }\end{array}$ & $\begin{array}{l}\text { Newly diagnosed } \\
\text { Relapsed }\end{array}$ & $\begin{array}{r}129 \\
54\end{array}$ & $\begin{array}{l}\text { Vincristine, actinomycin, } \\
\text { doxorubicin, cyclophosphamide }\end{array}$ & $\begin{array}{l}145 \\
159\end{array}$ \\
\hline $\begin{array}{l}9 / F \\
10 / M \\
11 / M\end{array}$ & $\begin{array}{l}11 \\
12 \\
12\end{array}$ & $\begin{array}{l}\text { Langerhans' malignancy } \\
\text { Schwannoma } \\
\text { Rhabdomyosarcoma }\end{array}$ & $\begin{array}{l}\text { Newly diagnosed } \\
\text { Newly diagnosed } \\
\text { Relapsed }\end{array}$ & $\begin{array}{l}96 \\
63 \\
63\end{array}$ & $\begin{array}{l}\text { Nil } \\
\text { Nil } \\
\text { Vincristine, actinomycin, } \\
\text { doxorubicin, cyclo- } \\
\text { phosphamide }\end{array}$ & $\begin{array}{l}137 \\
133 \\
134\end{array}$ \\
\hline
\end{tabular}

${ }^{*}$ PNET = primitive neuroectodermal tumour. 
However, patient 2 had evidence of partial left ureteric obstruction caused by his pelvic rhabdomyosarcoma, and patient 3 had a single kidney after resection of his Wilms' tumour. Eight children were studied from course number one, while three were studied from courses number three, four, and five respectively.

Nine patients received ifosfamide as a continous infusion at a dose of $9 \mathrm{~g} / \mathrm{m}^{2}$ given over three days with the same dose of mesna, and accompanied by $31 / \mathrm{m}^{2} /$ day of fluid. The hydration and mesna were continued for a further 12 hours after completion of the ifosfamide infusion. Two patients on relapse protocols were started at a lower dose of $6 \mathrm{~g} / \mathrm{m}^{2}$ given over two days. Concomitant treatment included vincristine and actinomycin $D$ or doxorubicin $(n=9)$, or etoposide $(n=2)$. Courses of treatment were given at intervals of three weeks. Dose reductions were performed, where indicated, by protocol instructions $(n=4)$.

\section{INVESTIGATIONS}

A sample of urine was collected immediately before each course of ifosfamide and again at completion of the mesna infusion. Samples were collected with azide preservative and frozen until analysed. Pretreatment plasma samples, collected at the same time, were analysed for concentrations of creatinine, electrolytes and phosphate and for alkaline phosphatase activity (American Monitor Parallel Analyzer). Plasma samples were collected after treatment from seven children (patients $2,3,4,6,8$, and 10 ) on a total of 34 occasions and the phosphate concentration measured.

To assess tubular function we measured urinary $\mathbf{N}$-acetyl-glucosaminidase (NAG), a brush border enzyme, and $\alpha_{1}$-microglobulin, a low molecular weight protein. We also measured albumin and transferrin as indicators of more generalised renal damage. Urinary creatinine concentration was measured (Beckman Astra) and proteins expressed as a creatinine ratio. In order to confirm patterns of either glomerular or tubular damage we performed urinary protein electrophoresis.

NAG was measured by colorometric assay (Cortecs Diagnostics), $\alpha_{1}$-microglobulin by single radial immunodiffusion, and albumin and transferrin by radioimmunoassay. Urinary protein electrophoresis was performed with sodium dodecyl sulphate polyacrylamide gel (SDS-PAGE) using a PhastSystem as previously described. ${ }^{7}$ Normal values for $\alpha_{1}$-microglobulin and transferrin were obtained from in house laboratory standards. For NAG, an upper limit of normal of $30 \mu \mathrm{mol} / \mathrm{hour} / \mathrm{mmol}$ creatinine was used, ${ }^{89}$ and for albumin an upper limit of $3 \mathrm{mg} /$ mmol creatinine was used. ${ }^{10}$

\section{FOLLOW UP STUDY}

Seven of the original 11 children were alive at a mean of seven months after completion of ifosfamide treatment. A single untimed urine sample was obtained and analysed for concentrations of NAG, $\alpha_{1}$-microglobulin, albumin, transferrin and creatinine, and protein electrophoresis was performed. None of the children had received any additional nephrotoxic treatment between completion of the ifosfamide treatment and the time of the follow up study.

\section{Results}

PROSPECTIVE STUDY

Sixty seven paired urine samples from before and after treatment were analysed. The results of the urinary markers are summarised in table 2.

\section{$N A G$}

The change in NAG values is represented graphically in fig 1 . All children started within

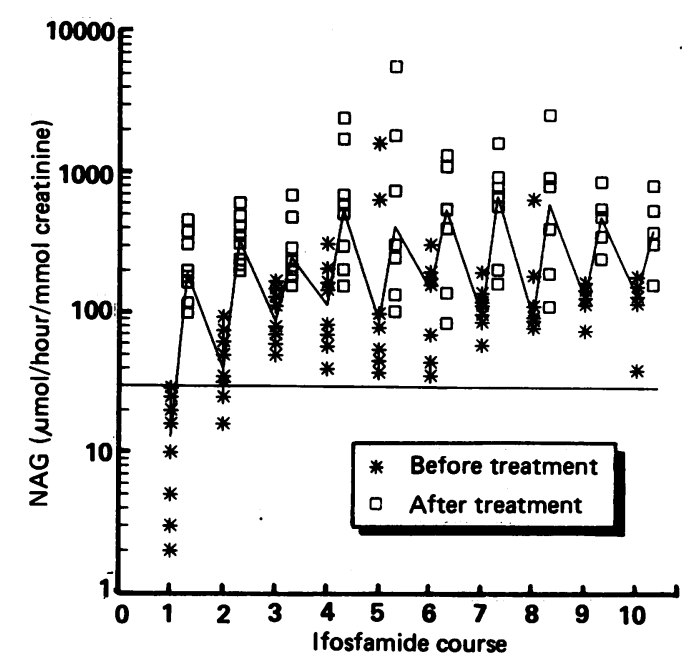

Figure 1 Urinary NAG concentrations before and after treatment. The solid line joins the median values. The horizontal line shows the upper limit of the normal range.

Table 2 Results of urinary markers before and after treatment. Results are median (range)

\begin{tabular}{|c|c|c|c|c|c|c|c|c|c|}
\hline \multirow{2}{*}{$\begin{array}{l}\text { No of } \\
\text { courses of } \\
\text { ifosfamide }\end{array}$} & \multirow{2}{*}{$\begin{array}{l}\text { No of } \\
\text { patients } \\
\text { studied }\end{array}$} & \multicolumn{2}{|c|}{ NAG (umol/hour/mmol creatinine) } & \multicolumn{2}{|c|}{$\begin{array}{l}\alpha_{1}-\text { Microglobulin (mg/mmol } \\
\text { creatinine) }\end{array}$} & \multicolumn{2}{|c|}{ Albumin (mg/mmol creatinine) } & \multicolumn{2}{|c|}{ Transferrin ( $\mu g / m m o l$ creatinine) } \\
\hline & & Before & After & Before & After & Before & After & Before & After \\
\hline $\begin{array}{r}1 \\
2 \\
3 \\
4 \\
5 \\
6 \\
7 \\
8 \\
9 \\
910\end{array}$ & $\begin{array}{l}8 \\
8 \\
8 \\
7 \\
7 \\
6 \\
7 \\
6 \\
5 \\
5\end{array}$ & $\begin{array}{c}15(1-20) \\
40(16-93) \\
88(50-148) \\
114(36-313) \\
89(32-1638) \\
169(30-313) \\
100(50-200) \\
95(50-190) \\
130(76-150) \\
136(40-160)\end{array}$ & $\begin{array}{l}192(100-455) \\
345(200-610) \\
246(162-691) \\
558(100-455) \\
319(103-5733) \\
560(86-1362) \\
708(166-1663) \\
617(113-2630) \\
500(251-1200) \\
388(164-1125)\end{array}$ & $\begin{array}{l}0.7(0.5-0.8) \\
0.9(0.2-16) \\
2.0(0.7-29) \\
1.9(0.9-27) \\
3.5(1-20) \\
3.2(1.8-8) \\
3.0(1-13) \\
3.6(2.5-8) \\
3.3(1.0-12) \\
4.5(1.6-13)\end{array}$ & $\begin{array}{l}5(2-30) \\
12(3 \cdot 7-88) \\
13(6-100) \\
12(4-65) \\
13(5-80) \\
15(6-55) \\
20(4-35) \\
22(10-38) \\
17(5-31) \\
16(10-34)\end{array}$ & $\begin{array}{l}0 \cdot 5(0 \cdot 2-2) \\
0.5(0 \cdot 2-3 \cdot 4) \\
1 \cdot 0(0 \cdot 6-2 \cdot 5) \\
1 \cdot 1(0 \cdot 4-4 \cdot 3) \\
1 \cdot 3(0 \cdot 6-124) \\
1 \cdot 3(0.6-108) \\
1 \cdot 7(0.6-18) \\
1 \cdot 2(0 \cdot 5-2 \cdot 7) \\
4 \cdot 1(0 \cdot 5-9) \\
2 \cdot 1(1 \cdot 1-10)\end{array}$ & $\begin{array}{l}2 \cdot 0(1 \cdot 2-14) \\
2 \cdot 7(0 \cdot 6-18) \\
3 \cdot 2(1 \cdot 4-60) \\
5 \cdot 3(1 \cdot 1-70) \\
10(1 \cdot 7-196) \\
2 \cdot 0(1 \cdot 3-66) \\
2 \cdot 8(2 \cdot 1-15) \\
5 \cdot 3(4-29) \\
6 \cdot 4(1 \cdot 9-39) \\
6 \cdot 7(2 \cdot 6-18)\end{array}$ & $\begin{array}{l}15(8-48) \\
15(4-117) \\
33(15-249) \\
20(10-357) \\
15(7-1303) \\
35(10-4720) \\
78(21-4469) \\
67(8-250) \\
71(40-445) \\
197(120-1581)\end{array}$ & $\begin{array}{l}20(15-108) \\
15(10-1900) \\
63(15-2348) \\
51(12-3691) \\
32(10-3373) \\
25(10-645) \\
40(7-2536) \\
221(10-1140) \\
205(40-596) \\
261(99-1322)\end{array}$ \\
\hline
\end{tabular}

Normal results: NAG $<30 \mu \mathrm{mol} / \mathrm{hour} / \mathrm{mmol} /$ creatinine, $\alpha_{1}$-microglobulin $<0.7 \mathrm{mg} / \mathrm{mmol}$-creatinine, albumin $<3 \mathrm{mg} / \mathrm{mmol} \mathrm{creatinine}$, and transferrin $<150$ $\mu \mathrm{g} / \mathrm{mmol}$ creatinine. 
the normal range. Each course of ifosfamide produced a rise in NAG values. Partial recovery occurred between treatments, but was incomplete and became less and less over the first three treatments. By the end of the third course, all values (including values before and after treatment) were outside the normal range. By the fourth course a plateau was reached and all values then remained abnormal, although there was no further progressive rise.

\section{$\alpha_{1}-$ Microglobulin}

An almost identical picture to that described for NAG was found for $\alpha_{1}$-microglobulin. The same progressive rise in pretreatment values was seen over the first three courses, with a uniform rise and fall occurring thereafter.

\section{Albumin}

Albumin also showed an acute individual treatment related rise (see fig 2). Unlike NAG and $\alpha_{1}$-microglobulin there was no progressive increase in pretreatment values, and most remained within the normal range for the duration of the treatment. Abnormal pretreatment values were seen only in two patients. They were patient 2 who had partial ureteric obstruction, and patient 9, where abnormal values were only seen after course number eight. The majority of values after treatment were abnormal, but showed a recovery before the next treatment.

\section{Transferrin}

Transferrin showed a variable treatment related effect, with no clear pattern evident. All patients started with normal values. Abnormal values were seen after course number two, and there was a slight upward trend of median values. Extremely high values (greater than $1000 \mu \mathrm{g} / \mathrm{mmol}$ creatinine) were seen in five patients $(1,2,3,5$, and 9$)$, although there was a large intrapatient variability.

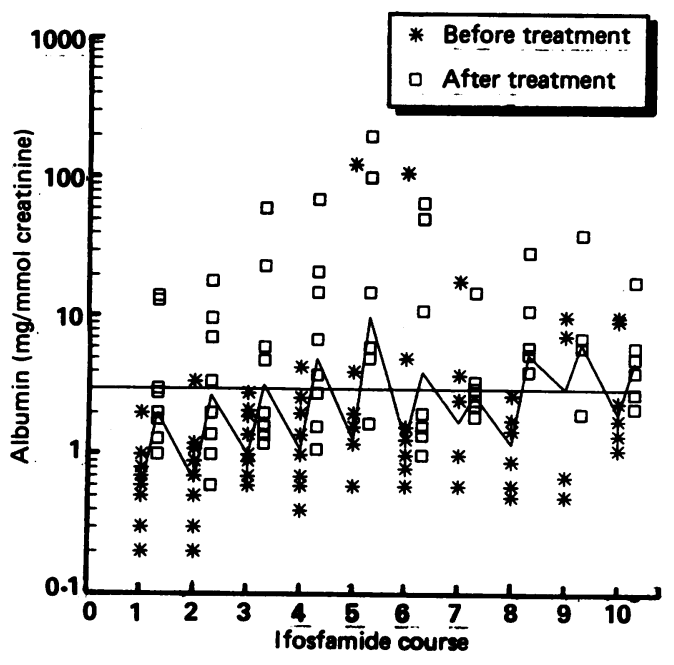

Figure 2 Urinary albumin concentrations before and after treatment. The solid line joins the median values. The horizontal line shows the upper limit of the normal range.

\section{Urine protein electrophoresis}

Electrophoretic patterns, with low molecular weight proteins, confirmed the development of generalised tubular proteinuria in all patients. The five patients with the high transferrin concentrations also showed a clear albumin and transferrin band. Generalised glomerular proteinuria with other high molecular bands, was only seen in patients 2 and 9 who had the very high pretreatment albumin concentrations. The majority of high albumin concentrations after treatment were associated with tubular, but not generalised glomerular patterns. Figure 3 shows the development of a generalised tubuloglomerular pattern in patient 2 .

\section{Plasma chemistry}

All patients had normal plasma creatinine concentrations over the duration of their ifosfamide treatment. All pretreatment phosphate concentrations remained within the normal range, except for patient 2 who had a pretreatment phosphate of $0.82 \mathrm{mmol} / \mathrm{l}$ on a single occasion. For the patients where phosphate was measured after treatment, there was a significant treatment related fall, with $40 \%$ of these phosphate values being below the lower limit of normal (see table 3 ). The remaining plasma chemistry was normal.

\section{FOLLOW UP STUDY}

Seven children were alive and available for follow up (table 4). All had abnormal NAG and $\alpha_{1}$-microglobulin concentrations. Five of the seven also had abnormal albumin and transferrin concentrations. These five patients also had grossly abnormal protein electrophoretic patterns indicating tubuloglomerular damage (see fig 4).

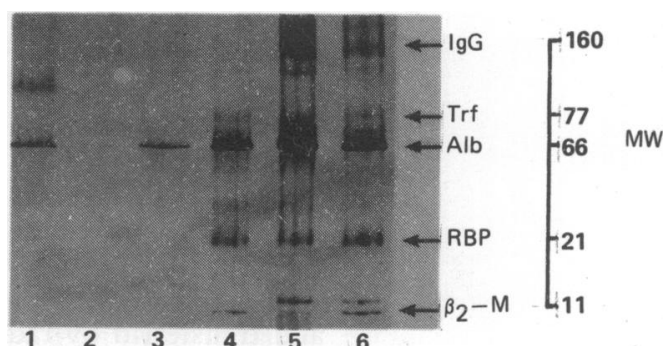

Figure 3 Urinary protein electrophoresis on patient 2. Tracks 1 and 2 are samples taken before and after ifosfamide course 2, tracks 3 and 4 from course 3, and tracks 5 and 6 from course 4. The progressive development of

tubuloglomerular pattern is shown. Molecular weight (MW) in kilodaltons is shown on the right. $T r f=$ transferrin, $A l b=$ albumin, $R B P=$ retinol binding protein, and $\beta_{2}-M=\beta_{2}$-microglobulin.

Table 3 Plasma phosphate concentrations

\begin{tabular}{|c|c|c|}
\hline & $\begin{array}{l}\text { Before } \\
\text { treatment }\end{array}$ & $\begin{array}{l}\text { After } \\
\text { treatment }\end{array}$ \\
\hline $\begin{array}{l}\text { No of paired samples } \\
\text { Concentration }(\mathrm{mmol} /)^{*} \text { : }\end{array}$ & 34 & 34 \\
\hline $\begin{array}{l}\text { Mean }(S D) t \\
\text { Range }\end{array}$ & $\begin{array}{l}1 \cdot 39(0 \cdot 23) \\
0 \cdot 82-2 \cdot 16\end{array}$ & $\begin{array}{l}1.02(0 \cdot 24) \\
0.4-1 \cdot 42\end{array}$ \\
\hline
\end{tabular}


Table 4 Follow up study

\begin{tabular}{|c|c|c|c|c|c|}
\hline $\begin{array}{l}\text { Patient } \\
\text { No }\end{array}$ & $\begin{array}{l}\text { Time since } \\
\text { completion of } \\
\text { ifosfamide } \\
\text { (months) }\end{array}$ & 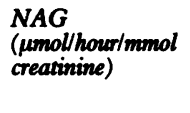 & $\begin{array}{l}\alpha_{1}-\text { Microglobulin } \\
\text { (mg/mmol } \\
\text { creatinine) }\end{array}$ & $\begin{array}{l}\text { Albumin } \\
\text { (mg/mmol } \\
\text { creatinine) }\end{array}$ & $\begin{array}{l}\text { Transferrin } \\
\text { ( } \mu \text { g/mmol } \\
\text { creatinine })\end{array}$ \\
\hline $\begin{array}{l}2 \\
3 \\
4 \\
5 \\
7 \\
8 \\
9\end{array}$ & $\begin{array}{r}6 \\
14 \\
6 \\
6 \\
7 \\
12 \\
11\end{array}$ & $\begin{array}{r}423 \\
119 \\
66 \\
50 \\
216 \\
69 \\
90\end{array}$ & $\begin{array}{c}41 \\
9 \cdot 5 \\
2 \cdot 3 \\
5 \\
17 \\
7 \\
25\end{array}$ & $\begin{array}{c}49 \\
215 \\
0.9 \\
1 \cdot 6 \\
25 \\
7 \\
14\end{array}$ & $\begin{array}{r}3023 \\
5614 \\
93 \\
78 \\
1708 \\
721 \\
819\end{array}$ \\
\hline
\end{tabular}

Normal results: NAG $<30 \mu \mathrm{mol} / \mathrm{hour} / \mathrm{mmol} /$ creatinine, $\alpha_{1}$-microglobulin $<0.7 \mathrm{mg} / \mathrm{mmol}$ creatinine, albumin $<3 \mathrm{mg} / \mathrm{mmol}$ creatinine, and transferrin $<150 \mu \mathrm{g} / \mathrm{mmol}$ creatinine.

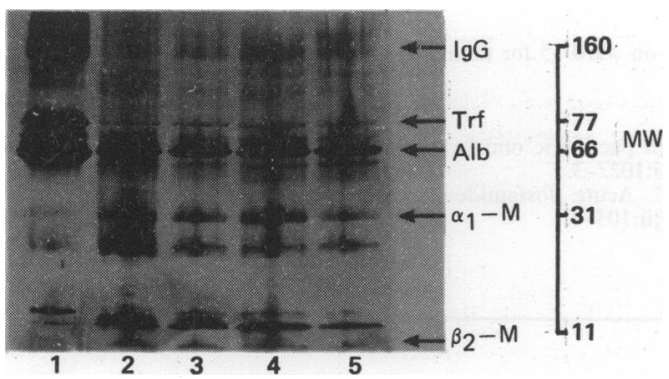

Figure 4 Follow up samples from patients 3 (track 1), 2 (2), 7 (3), 8(4), and 9(5) respectively. Sample for patient 3 was diluted 1:2. All five patients have a generalised tubuloglomerular pattern. Molecular weight $(M W)$ in kilodaltons is shown on the right. Trf=transferin, $A l b=a l b u m i n, \alpha_{1}-M=\alpha_{1}$-microglobulin, and $\beta_{2}-M=\beta_{2}-$ microglobulin.

\section{Discussion}

This study documents the pattern of tubular and glomerular damage occurring in patients receiving ifosfamide.

A progressive increase in pretreatment renal tubular markers was seen in all patients over the first three to four courses of treatment. Thereafter a uniform zigzag pattern was maintained. Urine protein electrophoresis confirmed the presence of generalised tubular proteinuria, which occurred in all patients. After the fourth course, recovery to normal concentrations was not seen. These findings are in contrast to those described by Goren et al, who found persistently abnormal pretreatment values in only one out of 18 patients. ${ }^{6}$ This may partly be due to the older age range of the patients studied by Goren et al. Measurement of plasma phosphate confirmed that for most of the children this damage was subclinical. Each ifosfamide treatment was usually associated with a fall in plasma phosphate, however, and in $40 \%$ of cases the phosphate concentration after treatment was abnormally low.

Albumin is classed as a glomerular protein. It is the smallest of the 'glomerular' proteins with a molecular weight of 66 kilodaltons, and its excretion rate is therefore affected by damage to the basement membrane. Like the tubular markers, albumin was also directly affected by ifosfamide, with increased concentrations seen after each ifosfamide treatment. Most pretreatment values remained within the normal range and there was no noticeable progressive rise.

Transferrin has similar physical characteristics to albumin, with a molecular weight of 77 kilodaltons. Transferrin is a complex molecule and is involved in a number of metabolic processes. ${ }^{11}$ Diferric transferrin is specifically concentrated by damaged tissue and actively proliferating cells. In the former it is associated with the superoxide dismutase reaction and in the latter with ribonucleotide reductase. In damaged renal tissue, active concentration of diferric transferrin will cause an increase in the intracellular concentration of apotransferrin which in turn will cause an increase passage of the molecule through the glomerulus. There was no uniform increase in urinary transferrin related to individual course of treatment. Each patient had a variable pattern with the highest values often occurring in the pretreatment sample. For most of the patients with appreciably raised transferrins, the urine protein electrophoresis did not show generalised glomerular damage. These facts indicate that transferrin was being handled differently to albumin and probably reflect an association with renal damage repair processes.

Generalised glomerular damage, as indicated by electrophoresis, occurred in only two patients during the prospective study. In one the presence of partial ureteric obstruction was a predisposing factor. Glomerular damage is therefore less noticeable and less acute than tubular damage. The presence of abnormal transferrin and abnormal albumin values after treatment in the majority of patients may point to a slowly accumulating glomerular damage, and thereby contribute to the striking follow up findings.

It would be helpful if known risk factors together with the use of urinary markers could predict the development of early and/or clinically significant toxicity. Underlying renal abnormalities are a known risk factor, and there is some evidence from the literature that young age may also be important. ${ }^{5}$ Though the development of microalbuminuria or even generalised proteinuria is clearly abnormal, the significance of a single finding may not be immediately apparent. It should nevertheless provide a warning for further evaluation.

This follow up study confirms the presence of tubular and glomerular damage found by Skinner et al. All patients showed abnormal tubular markers. It is therefore not surprising that patients may present late with hypophosphataemic rickets and Fanconi's syndrome. While all these patients are exposed to a number of potentially nephrotoxic drugs during their prolonged course of treatment, it appears from this 
study that ifosfamide is a significant contributory factor to persisting tubular damage.

The presence of generalised glomerular damage in five out of seven patients at follow up is worrying in that it suggests the possibility of progressive glomeruler damage in some patients. Further follow up studies will be needed to establish if any recovery occurs with time. It is clear that all patients receiving ifosfamide need to be closely monitored for renal toxicity, not only during treatment, but also at follow up. In addition, these findings need to be taken into account in the debate on the therapeutic role of ifosfamide. We wish to thank the nursing staff on ward 15 for their help in
collection of specimens.

1 Shaw PJ, Eden T. Ifosfamide in paediatric oncology: tried but not tested? Lancet 1990;i:1022-3.

2 Heney D, Lewis IJ, Bailey CC. Acute ifosfamide-induced tubular toxicity. Lancet 1989;ii:103-4.
3 Skinner R, Pearson ADJ, Price L, Cunningham K, Craft AW. Hypophosphataemic rickets after ifosfamide treatAW. Hypophosphataemic rickets after ifo
ment in children. $B M \mathcal{Y}$ 1989;298:1560-1.

4 Smeitink J, Verreussel M, Schroder C, Lippens R. Nephrotoxicity associated with ifosfamide. Eur f Pediatr 1988;148: toxicity

5 Skinner R, Pearson ADJ, Price L, Coulthard MG, Craft AW. Nephrotoxicity after ifosfamide. Arch Dis Child 1990;65: 732-8.

6 Goren MP, Pratt CB, Viar MJ. Tubular nephrotoxicity during long-term ifosfamide and mesna therapy. Cancer Chemother Pharmacol 1989;25:70-2.

7 Jackson PJ, Sampson CJ, Cooper EH, Heney D, Brocklebank JT. Analysis of proteinuria using a commercial system for automated electrosesis and isoelectric focusing. Ann Clin Biochem 1988;25:319-24.

8 Osborne J. Urinary excretion of $\mathrm{N}$-acetyl-glucosaminidase in children. Arch Dis Child 1980;55:719-21.

9 Kunin CM, Chesney RW, Craig WA England AC, unin CM, Chesney RW, Craig WA, England AC, DeAngelis C. Enzymuria as a marker of renal injury and disease. Studies of $\mathrm{N}$-acetyl-glucosaminidase in the general population and in patients with renal disease. Pediatrics

10 Davies AG, Postlethwaite RJ, Price DA, Burn JL, Houlton CA, Fielding BA. Urinary albumin excretion in school children. Arch Dis Child 1984;59:625-30.

11 Cazzalo M, Bergamaschi G, Dezza L, Arosio P. Manipulations of cellular iron metabolism for modulating normal and malignant cell proliferation: achievements and prospects. Blood 1990;75:1903-19.

.... and carrying colicky babies

A study from McGill University, Montreal, published in 1986 showed that crying was significantly less in mothers of normal babies who were asked to increase the time for which they carried their babies when they were not crying. ${ }^{1}$ So if it works for normal babies why not for colicky babies? Which begs the question: are colicky babies different or are they simply the upper end of the normal range as regards crying?

The same workers in Montreal (Ronald G Barr and colleagues, Pediatrics 1991;87:623-30) have carried out a randomised controlled trial of extra carrying in infant colic. They defined colic as excessive crying in a young baby which was both presented as a problem by the mother and seen as a problem by the doctor. Seventy eight mother-baby pairs were recruited of whom 12 did not complete the study. All the babies were less than 29 days old on entry to the study. Of the 66 who completed the study 35 were assigned to 'standard treatment'. That is the mothers were advised to respond to their babies crying by comforting them, to breast feed them if appropriate, to give them smaller more frequent feeds if bottle fed, to place the baby in a seat near to mother, and to use distractions such as music or a car ride. The other 31 were given the same advice but in addition were advised to carry their babies for at least an extra three hours a day.

There was no significant difference in crying or fussing behaviour between the two groups. This result needs to be interpreted with caution, however. Both groups of babies were given a lot of attention by their parents and at entry to this study the mothers were already carrying their babies as much as did the mothers in the previous study who increased their carrying (just over four hours each day). ${ }^{1}$ Perhaps four hours a day is enough and carrying more than that produces no benefit. A previous study has shown parent counselling to be more effective than cows' milk avoidance. ${ }^{2}$

A sensible approach seems to be to advise parents to be responsive to their babies and to carry them up to four hours a day. If such measures don't work then cows' milk avoidance by either the baby or the breast feeding mother should be considered. 